\title{
Study on vocal music and Chinese traditional literature
}

\author{
Shan Wang, Yang Li \\ Xingtai University, Xingtai, 054000, China
}

\author{
Keywords: Vocal music, Traditional literature, Language, Study
}

\begin{abstract}
Chinese traditional literature and vocal music are gems in China's cultural treasure, and they are also inextricably linked each other. China's traditional literature has a complete knowledge system. Combining it with vocal music, it can achieve icing on the cake, complementary artistic effect. With the changes of history and development of society, China's vocal art has been dramatically improved and has gradually formed a well-structured system in the tide of the times. In this paper, the characteristics of vocal music and traditional Chinese literature have been discussed, and the links between vocal music and traditional literature have been analyzed.
\end{abstract}

\section{Introduction}

Vocal music and traditional literature are the most representative forms of artistic expression in the history of human civilization. In this long history of human development, vocal and literary mutual promotion and common development, although both are independent form of artistic expression, but off the vocal or independently existing literature literary art form because of a single, often a bit boring, therefore, in the artistic expression often lyrical and vocal literature describing organically combine to make the viewer feel a double psychological and aesthetic senses.

\section{Vocal music art in China}

Art is a social ideology with the development and progress of human civilization and evolving, both as a cultural phenomenon, but also an aesthetic expression. Vocal Arts is a whole art system, creation, singing, work, teaching, comments and other artistic activity includes vocal music, vocal music in our history of thousands of years has made brilliant achievements ${ }^{[1]}$. Development of vocal music in the Han Dynasty have a high artistic attainments, when people have been able to master the basic vocal skills, vocal art will cooperate with the pitch system, resulting in a perfect artistic effect, forming a system of aesthetic consciousness. Under the influence of social changes, all ethnic groups were vocal art organic integration, will have the characteristics of each ethnic music ingenious combination of firmness and flexibility, a unique form of artistic expression.

\section{The characteristics of China's vocal music and traditional literature}

Vocal music and traditional literature in the development of the changing times gradually formed its own artistic characteristics. States vocal and literature have nationality, mostly showing the nation's customs and cultural heritage. In the vocal arts, singing standards around the world are unified. Therefore, in order to show the art of singing the national characteristics, it is necessary to comply with standards, based on singing, vocal highlight areas of distinctive national character.

China is an ancient country which has five thousand years' history of civilization, and it contains numerous literary classics. In the development of Chinese culture, the traditional literature and vocal music has always had close ties, both interdependent and affect each other. Such as folk songs in the Han Dynasty, poems in Tang and Song dynasties and popular dramas verses in Yuan dynasty express the dependencies between literature and vocal music ${ }^{2]}$.

Chinese vocal music has distinctive ethnic characteristics, to ensure long-term stable development of Chinese vocal music, vocal music is necessary to combine science and nationality, using precise pronunciation skills, continuous reform and innovation manifestations of Chinese vocal music. 
Meanwhile, as an important expression vector of vocal music, lyrics must cooperate with the melody, full of national characteristics of Chinese vocal music.

\section{The relationship between vocal music and traditional Chinese literature}

\section{There is uniformity between vocal music and traditional Chinese literature}

Both vocal music and traditional literature are important art expression forms, and they have certain uniformity on development and expression, which expresses on he following aspects.

Both vocal music and traditional Chinese literature are influenced by geographical conditions

It has been found through the majority of experts and scholars study that the geographical environment has an important impact on the emergence and development of the arts. Vocal music style and traditional Chinese literature under the influence of geographical factors, generate uniformity ${ }^{[3]}$. As some of the northwest plateau, landforms ravines, ground undulating, open terrain, sparse vegetation, so the resulting high-pitched vocal art mostly simple, artistic conception of melody features, including "Xin TianYou" the most representative. In the literature, many works exhibited Majestic, bold comfortable writing style, such as the Tang Dynasty poet Cen Sen's "Walking on horse Mr. Feng apprenticeship for western expedition", this poem forthright statement, agitation heroic, learn to grasp the features of the scene description of the environment dangerous to bring out the soldiers dauntless heroism.

Both vocal music and traditional literature are expression of emotion

The main connotation of vocal music is to express feelings, precisely because the vocal music is the performance of the human inner world, so it can make people in different races; different background and different environments produce spiritual resonance. Literature is the author's own traditional cultural expression, the inner world of the author in his writings bloom product. In the development of the times, everyone's outlook on life, values, world view will be different, which leads to feelings and understanding people look at the same work when there are significant differences, but this is the world of the performance of the human heart, in essence, have unity. As a Chinese film Song of the Fishermen in last century theme song, the song lyrics and the use of real rustic euphemism melancholy melody, vividly shows a fishing village viewer bankruptcy bleak picture, showing a miserable old society of fishermen encounter, works full of blood and tears masses of working people, the feelings of sincere sadness. In literature, Bai Juyi's "The song of a lute" has some representation. This poem to love moving, using a simple narrative technique, so that the poet inner feelings fleshed poet deep inside the rich and delicate feelings show in front of the reader. Although the vocals and traditional literature there are some differences in the form of performance, but it does have the unity of the inner essence ${ }^{[4]}$.

Both vocal music and traditional literature are development of human language

Language is mankind's most important communication tool, precisely because of the existence of language, human civilization was able to develop and heritage. Vocal and traditional literature are made on the basis of language development and extension. Vocal is the essence of the art world is full of language arts. For example Yuefu Poems of Han Dynasty "the Peacock Flies to the Southeast," which is the background of the story-song chant elegy. The whole song is by refining the text narrative and character language, the use of singing sad melody; vividly express a desolate atmosphere of the entire song. Literary works of art formed by the description language, literary works by high-level overview of the language, to make the reader feel the charm of written language. Such as poet Wang Ji Liang's work "Into Ruoye Brook" poem "Chanzao forest over static more secluded mountain birds" use foil technique, the "noise of cicadas" to highlight the "Lin Jing", with "birds" the performance of "secluded mountain", combining static and dynamic, the beauty of nature in the form of performance out of words, the language just right, it is like being in the quiet of nature distant environment ${ }^{[5]}$. 


\section{Compatibility exists between vocal music and traditional Chinese literature}

Based on the intrinsic link between vocal music and traditional literature, the integration of the two can effectively enhance the viewer's aesthetic experience. First, most of the literature poetry can directly sing, and with changing times, become a classic, such as the song based on the Song Dynasty poet Su Shi's "Prelude To Water Melody • When will the moon be clear and bright? ", the content of the original poem almost do changes, with singer tune difference gradually formed styles of classic tracks. There Su Shi 's Charm • Kingdoms ", the Tang Dynasty poet Li Bai's "Hard on the road" etc., are carried through poetry singing, forming a classic. Second, in the literature, there is also that in accordance with "sound and feeling" at the request of original works deduction. Such as the Tang Dynasty poet Wang Wei's "Weicheng Qu", the singer in the history of its interpretation of the process, from the initial Seven quatrains gradually evolved into a content-rich "long words" that "Yangguan Farewell." This process makes the interpretation of the original poem to express the grief of parting is more prominent, rich inner emotional work of art.

Whether singing songs based on traditional literature, or vocal richness of the original interpretation, all vividly expressed the intrinsic link vocals and traditional literature, strongly suggests that the integration of vocal music and traditional literature, not only so that the two complement each other, but also exhibit more powerful artistic charm.

\section{Vocal music and traditional Chinese literature interdepends and supplements each other}

Vocal music and literature, although there are differences in the form of expression, but there are also relatively close link between the two. Excellent vocal works in addition to a beautiful melody and strong rhythm, there should be a good lyricist. A good vocal works included the lyricist and composer's thoughts and feelings, expression vectors such feelings are the music of words and music.

Vocal music is the best form of traditional literature. For example, Book of Songs divides the songs into three parts including Feng, Ya and Song, where Feng refers to local music in different areas, including the folk songs from 15 regions, most of which are folk songs; Ya refers to the music in the Zhou Dynasty Territory areas which are songs for palace banquets and other activities, and Song refers to the ancestral worship when singing the song, most of the content is the ancestor of merit praise. As can be seen from these songs, the earliest literary poetry exists in the form of vocal music, showing our traditional literature in ancient times and vocal music are closely linked. Only achieve unity between artistic and traditional vocal literature, interdependent and mutually reinforcing, in order to truly become a perfect work of art.

\section{The innovation of vocal music and traditional Chinese literature}

In the recitation of a literary work, pay attention to the extremely rich, this principle also applies to vocal music and traditional literature. For example, direct the concert literature, to combine sound and emotion, into the appropriate emotion in the singing.

\section{The aesthetic ideology of vocal music and traditional Chinese literature}

Human life cannot lack vocal and literature, which enrich our daily life; it brings us the ultimate aesthetic experience. Therefore, we have to vocal music and literature into everyday life, to achieve the unity of art and life. With the improvement of people's living standards, the demand for literature and art is also increasing. There is an urgent need to experience a higher level of artistic realm from life, cultivate a new aesthetic concept from the union of poetry and music. With the progress and development of the times and society, the relationship between vocal and traditional literature more closely, we must continue to innovate in the form of vocal performance, vocal music and promote the combination of Chinese traditional literature on the traditional literary heritage and development, rich vocal Arts in fresh elements to achieve coordinated development of vocal music and traditional literature. 


\section{Conclusions}

In summary, vocal music and traditional Chinese literature links, but also they have essential differences; both of them are important medium to convey thoughts and feelings, to express the sincere human emotion. The development of vocal music can highlight China's national characteristics, but also it may promote national cultural progress. Traditional Chinese vocal music literature for the development into a fresh force, using a unique form of artistic expression so vocal in the arts occupy a place, so we have to take advantage of the intrinsic link vocals and traditional literature, and promote common development of the two, add more cultural elements of the arts in China.

\section{References}

[1] Liu Qiu'e, Liu Bo. Exploration on Chinese literature tradition and Chinese vocal music. Youth Times, 2015(6):11-11.

[2] Ji Guoqiang. Chinese literary tradition and Chinese vocal music. Hanjiang Forum, 2014(9):119-122.

[3] Shi Weizheng. The combination of music and literature in vocal music art. People's Music (Review edition), 2012(5):46-48.

[4] Yu Yingzi. Poetry as core of music, sound as frame of music - taking Chinese classical songs as example to analyze the relation between vocal music and literature. China Education outside school,2012(1):157-157.

[5] Zeng Xian. On relevance between music and literature and development. Times Literary, 2012(11):230-231. 